\title{
Klasifikasi Beras Menggunakan Metode K-Means Clustering Berbasis Pengolahan Citra Digital
}

\author{
Atriyan Trisnawan ${ }^{1)}$, Wahyudi Harianto ${ }^{2)}$, Syahminan ${ }^{3)}$ \\ 1,2,3) Teknik Informatika Fakultas Sains Dan Teknologi Universitas Kanjuruhan Malang \\ atriyan1994@gmail.com, wahyou@unikama.ac.id, syahminan@unikama.ac.id
}

\begin{abstract}
Rice plants (Oryza Sativa L.) are important food crops that have become a staple food for more than half of the world's population. In Indonesia rice is the main commodity in supporting community food. The process of processing rice into rice is done in two ways, namely the processing of pulverized and modern processing using a grinding tool. Rice is an important component in daily food. There are several types on the market, namely: fragrant pandan rice, IR 64, IR 42, C 4, and others. With the variety of forms and types of rice on the market, there are many weaknesses that humans have in perceiving the classification of rice using the senses of vision. Therefore, digital image processing techniques are needed to help analyze the type of rice. This study aims to analyze the type of rice using the K-Means Clustering method based on RGB colors. Before the $K$-Means calculation, the RGB color feature extraction process must be carried out to get the red value, green value, blue value in each image. The results of this study found that image processing to determine the type of rice using the k-means clustering method can help users to know the type of rice.
\end{abstract}

Keyword : Analysis; Rice; K-Mean Clustering; Digital Image Processing.

\begin{abstract}
Tanaman padi (Oryza Sativa L.) merupakan tanaman pangan yang penting yang telah menjadi makanan pokok lebih dari setengah penduduk dunia. Di Indonesia padi merupakan komoditas utama dalam menyokong pangan masyarakat. Proses pengolahan padi menjadi beras dilakukan dengan dua cara yaitu proses pengolahan ditumbuk dan proses pengolahan modern memakai alat penggilingan. Beras merupakan komponen penting dalam makanan sehari-hari. Ada beberapa jenis yang beredar di pasaran yaitu : beras pandan wangi, IR 64, IR 42, C 4, dan lain-lain. Dengan benareka ragam bentuk dan jenis beras di pasaran banyak kelemahan yang dimiliki manusia di dalam mempersepsi klasifikasi jenis beras menggunakan indera penglihatan.Oleh karena itu, teknik pengolahan citra digital diperlukan untuk membantu menganalisa jenis beras. Penelitian ini bertujuan untuk menganalisa jenis beras menggunakan metode K-Means Clustering berdasarkan warna RGB. Sebelum dilakukan perhitungan K-Means, harus dilakukan proses esktrasi fitur warna RGB untuk mendapatkan nilai red, nilai green, nilai blue pada tiap citra. Hasil dari penelitian ini didapatkan bahwa image processing untuk menentukan jenis beras menggunakan metode k-means clustering dapat membantu pengguna untuk mengetahui jenis beras.
\end{abstract}

Kata Kunci : Analisa; Beras; K-Mean Clustering; Digital Image Processing.

\section{Pendahuluan}

padi (Oryza Sativa L.) merupakan tanaman pangan yang penting yang telah menjadi makanan pokok lebih dari setengah penduduk dunia. Di Indonesia padi merupakan komoditas utama dalam menyokong pangan masyarakat. Makanan lokal seperti umbi-umbian tidak mampu menggeser keberadaan tanaman padi sebagai pangan pokok. Terdapat 18 juta petani padi di Indonesia yang menyumbang $66 \%$ terhadap produk domestik bruto (PDB) tanaman pangan.

Di Indonesia proses pengolahan padi menjadi beras dilakukan dengan dua cara yaitu proses pengolahan ditumbuk dan proses pengolahan modern memakai alat penggilingan. Proses pengolahan paska panen di Indonesia identik menggunakan penggilingan modern. Beras merupakan komponen penting dalam makanan sehari-hari. Ada beberapa jenis yang beredar di pasaran yaitu : beras pandan wangi, rojo lele, IR 64, IR 42, C 4, dan lain-lain. Dengan benareka ragam bentuk, warna dan jenis beras di pasaran banyak kelemahan yang dimiliki manusia di dalam mempersepsi klasifikasi jenis beras menggunakan indera penglihatan

Pada penelitian kali ini, penelitian mencoba menggunakan teknik dengan pendekatan metode untuk menentukan analisa dan pengelompokan jenis beras dengan pendekatan menggunakan pencitraan dengan judul "Klasifikasi beras menggunakan Metode K-Means Clustering Berbasis pengolahan citra digital". 
Maka dengan majunya teknologi dan informasi, dibidang digital image processing. Untuk mengatasi permasalahan jenis beras, maka disini penulis akan berusaha membuat suatu aplikasi yang menggunakan metode k-means clustering yang nantinya dapat digunakan untuk menentukan klasifikasi beras. Berdasarkan permasalahan di atas

\section{Metode}

1. Alat Pendukung

Alat pendukung yang digunakan dalam penelitian ini adalah sebagai berikut:

1. Perangkat Keras:

- Laptop processor core i3

- Ram 6GB

- Hardisk 500GB

- LCD 14"

2. Perangkat Lunak:

- $\quad$ Sistem Operasi Windows 7 Ultimate

- $\quad$ Borland Delphi 7

- $\quad$ Microsoft Access 2013

- $\quad$ Microsoft Office Word 2013

- Alpha Skins

\section{Tahapan Penelitian}

Tahapan penelitian merupakan langkah-langkah yang akan dilakukan peneliti dalam melakukan penelitian. Tahapan yang dilakukan dalam penelitian ini meliputi studi literatur,

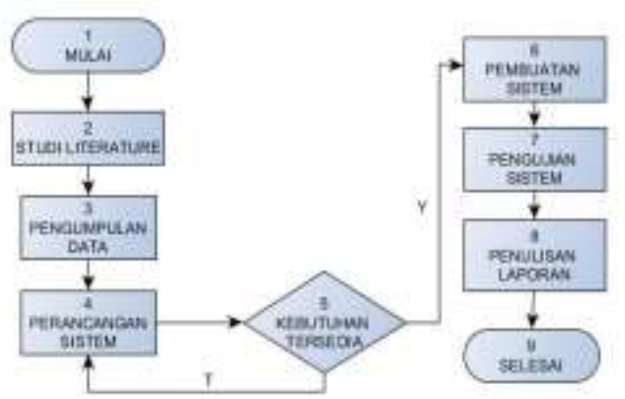

pengumpulan data, perancangan sistem, pembuatan sistem, pengujian sistem, dan pembuatan laporan. Bagan tahapan penelitian disajikan pada Gambar 1.

\section{Perhitungan K-means Clustering}

$K$-means clustering adalah salah satu algoritma dalam menentukan klasifikasi terhadap objek berdasarkan fitur dari objek tersebut kedalam K kluster. K adalah angka positif yang menyatakan jumlah grup/kluster/partisi terhadap objek. Pemartisian data dilakukan dengan mencari nilai jarak minimum antara data dan nilai centroid yang telah di set baik secara random atau pun dengan initial set of centroid, kita juga dapat menentukan nilai centroid berdasarkan K objek yang berurutan.

Centroid adalah nilai rata-rata aritmetik dari sebuah objek dari seluruh titik dalam objek tersebut. Penerapan K-means clustering ini dapat dilakukan dengan prosedur step by step berikut: 


\begin{tabular}{|l|l|l|l|l|l|}
\hline No & Data & R & G & B & Pixel \\
\hline 1 & B1 & 4497322 & 287410 & 280391 & 255 \\
\hline 2 & B2 & 4519442 & 316529 & 296287 & 255 \\
\hline 3 & B3 & 4464346 & 255928 & 250218 & 255 \\
\hline 4 & B4 & 4499680 & 290553 & 276541 & 255 \\
\hline 5 & B5 & 4483034 & 275847 & 264708 & 255 \\
\hline 6 & B6 & 4484693 & 277393 & 265664 & 255 \\
\hline 7 & B7 & 4471565 & 261805 & 250235 & 255 \\
\hline 8 & B8 & 4466688 & 258150 & 242576 & 255 \\
\hline 9 & B9 & 4492792 & 286712 & 284523 & 255 \\
\hline 10 & B10 & 4485676 & 273983 & 265215 & 255 \\
\hline
\end{tabular}

Akan dilakukan pemartisian data terhadap data diatas sebanyak lima (5) partisi, maka tahapannya adalah sebagai berikut:

1. $\mathrm{K}=5,(\mathrm{~K}=\mathrm{Jumlah}$ Cluster)

2. Nilai awal centroid (4519442, 316529, 296287) untuk partisi 1, centroid (4499680, 290553, 276541) untuk partisi 2, centroid $(4484693,277393,265664)$ untuk partisi 3, centroid $(4471565,261805,250235)$ untuk partisi 4, centroid $(4485676,273983,265215)$ untuk partisi 5

3. Maka perhitungan Euclidean Distance adalah

$\left.D(p, c)_{0}=\sqrt[2]{\sum_{i=0}^{n}\left(p_{i}\right.}-c_{i}\right)^{2}$

dimana $\boldsymbol{p}$ adalah data, $\boldsymbol{c}$ adalah centroid, $\mathrm{n}$ adalah jumlah data, I adalah iterasi.

4. Hasil perhitungan jarak minimum B1 adalah

$$
\begin{gathered}
D(p, c)_{1}=\sqrt{(4497322-4519442)^{2}}+(287410-316529)^{2}+(280391-296287)^{2} \\
=70886281111584 \\
\begin{array}{c}
D(p, c)_{1}=\sqrt{(4497322-4499680)^{2}}+(287410-290553)^{2}+(280391- \\
276541)^{2}=67247626671623 \\
(287410-277393)^{2}+(280391-265664)^{2} \\
=69886281111584 \\
=6(p, c)_{1}=\sqrt{(4497322-4484693)^{2}}+ \\
D(p, c)_{1}=\sqrt{(4497322-4471565)^{2}}+(287410-261805)^{2}+(280391-250235)^{2} \\
D(p, c)_{1}=\sqrt{(4497322-4485676)^{2}}+(287410-273983)^{2}+(280391-265215)^{2} \\
=100886281111584
\end{array}
\end{gathered}
$$

5. Hasil perhitungan jarak keseluruhan

\begin{tabular}{|l|l|l|l|l|l|}
\hline Data & C1 & C2 & C3 & C4 & C5 \\
\hline B1 & 7088 & 67247 & 69886 & 90886 & 100886 \\
& 6281 & 62667 & 28111 & 28111 & 281111 \\
& 1115 & 1623 & 1584 & 1584 & 584 \\
& 84 & & & & \\
\hline B2 & 0 & 21833 & 24162 & 39862 & 261242 \\
& & .8374 & .0860 & .3754 & 474970 \\
& & 7764 & 4404 & 5606 & 5 \\
\hline B3 & 6062 & 34002 & 63058 & 93958 & 088628 \\
& 5.88 & 5.886 & .2659 & .5000 & 111158 \\
\hline
\end{tabular}




\begin{tabular}{|c|c|c|c|c|c|}
\hline & $\begin{array}{l}6104 \\
86\end{array}$ & 10486 & 8472 & 8381 & 4 \\
\hline B4 & $\begin{array}{l}3336 \\
6.53 \\
3383 \\
01\end{array}$ & 0 & $\begin{array}{l}30918 \\
.7322 \\
6702\end{array}$ & $\begin{array}{l}38316 \\
.6445 \\
2990\end{array}$ & $\begin{array}{l}385488 \\
048771 \\
94\end{array}$ \\
\hline B5 & $\begin{array}{l}2271 \\
7.94 \\
2204 \\
34\end{array}$ & $\begin{array}{l}25166 \\
.9353 \\
38300\end{array}$ & $\begin{array}{l}38136 \\
.6445 \\
2990\end{array}$ & $\begin{array}{l}54947 \\
.6464 \\
9484\end{array}$ & $\begin{array}{l}672476 \\
266716 \\
23\end{array}$ \\
\hline B6 & $\begin{array}{l}3854 \\
8804 \\
8771 \\
94\end{array}$ & $\begin{array}{l}26833 \\
82948 \\
8166\end{array}$ & 0 & $\begin{array}{l}41838 \\
36807 \\
8834\end{array}$ & $\begin{array}{l}126124 \\
247470 \\
5\end{array}$ \\
\hline B7 & $\begin{array}{l}3757 \\
6576 \\
1384 \\
66 \\
\end{array}$ & $\begin{array}{l}26124 \\
24747 \\
052\end{array}$ & $\begin{array}{l}70886 \\
28111 \\
1584\end{array}$ & 0 & $\begin{array}{l}378967 \\
178190 \\
93\end{array}$ \\
\hline B8 & $\begin{array}{l}3819 \\
6104 \\
1487 \\
21\end{array}$ & $\begin{array}{l}12612 \\
42474 \\
705\end{array}$ & $\begin{array}{l}37576 \\
57613 \\
8466\end{array}$ & $\begin{array}{l}56798 \\
.3939 \\
494\end{array}$ & $\begin{array}{l}418383 \\
680788 \\
34\end{array}$ \\
\hline B9 & $\begin{array}{l}4183 \\
8368 \\
0788 \\
34\end{array}$ & $\begin{array}{l}57597 \\
04453 \\
3552\end{array}$ & $\begin{array}{l}38191 \\
.0414 \\
8721\end{array}$ & $\begin{array}{l}26124 \\
24747 \\
050\end{array}$ & $\begin{array}{l}418383 \\
680788 \\
34\end{array}$ \\
\hline B10 & $\begin{array}{l}3789 \\
6.17 \\
8190 \\
93\end{array}$ & $\begin{array}{l}15692 \\
.4308 \\
9568\end{array}$ & $\begin{array}{l}67869 \\
.2430 \\
89568\end{array}$ & $\begin{array}{l}38548 \\
.0487 \\
7194\end{array}$ & 0 \\
\hline
\end{tabular}

Hasil perhitungan partisi diambil dari jarak minimum, sehingga di dapat sebagai berikut:

\begin{tabular}{|l|l|l|l|l|l|}
\hline Data & C1 & C2 & C3 & C4 & C5 \\
\hline B1 & 0 & 1 & 0 & 0 & 0 \\
\hline B2 & 1 & 0 & 0 & 0 & 0 \\
\hline B3 & 0 & 1 & 0 & 0 & 0 \\
\hline B4 & 0 & 1 & 0 & 0 & 0 \\
\hline B5 & 0 & 1 & 0 & 0 & 0 \\
\hline B6 & 0 & 0 & 1 & 0 & 0 \\
\hline B7 & 0 & 0 & 0 & 1 & 0 \\
\hline B8 & 0 & 1 & 0 & 0 & 0 \\
\hline B9 & 0 & 0 & 0 & 1 & 0 \\
\hline B10 & 0 & 0 & 0 & 0 & 1 \\
\hline
\end{tabular}

Pada C2 67247626671623 lebih kecil dari C1 70886281111584, C3 69886281111584, C4 90886281111584, C5 100886281111584 maka T1 termasuk ke dalam Cluster 2.

6. Setelah data di partisi, maka selanjutnya nilai centroid harus dihitung ulang untuk menentukan centroid baru:

$$
c_{i}^{(t+1)}=\frac{1}{\left|S_{i}^{(t)}\right|} \sum_{P j \in S_{i}^{(t)}} P_{j} \mid
$$




$$
\begin{aligned}
& c_{1}=\left(\begin{array}{c}
\frac{(4497322+4519422)}{2}, \\
\frac{(287410+316529)}{2}, \\
\frac{(280391+296287)}{2}
\end{array}\right)=5098036,7554512,7312517 \\
& c_{2}=\left(\begin{array}{l}
\frac{(464346+4499680)}{2}, \\
\frac{(255928+290553)}{2}, \\
\frac{(250218+276541)}{2}
\end{array}\right)=5760220,5569626,5224930 \\
& c_{3}=\left(\begin{array}{c}
\frac{(4483034+4484693)}{2}, \\
\frac{(275847+277393)}{2}, \\
\frac{(264708+265664)}{2}
\end{array}\right)=5775815,581726,5276042 \\
& c_{4}=\left(\begin{array}{l}
\frac{(4471565+4466688)}{2}, \\
\frac{(261805+258150)}{2}, \\
\frac{(250235+242576)}{2}
\end{array}\right)=5647232,5659580,5430346 \\
& c_{5}=\left(\begin{array}{l}
\frac{(4492792+4485676)}{2}, \\
\frac{(2686712+273983)}{2}, \\
\frac{(284523+265215)}{2}
\end{array}\right)=5870871,5661924,5439344
\end{aligned}
$$

7. jarak minimumnya kembali dengan menggunakan centroid yang baru, sehingga didapat hasilnya sebagai berikut:

$$
\begin{aligned}
& D(p, c)_{0}=\sqrt{(9622437-6511822)^{2}}+(9536920-63492876)^{2} \\
& +(9416651-60412542)^{2}=80494838245916 \\
& D(p, c)_{1}=\sqrt{(9622347-5861628)^{2}}+(9536920-5661660)^{2} \\
& +(9416651-5432017.8)^{2}=67113286495484 \\
& D(p, c)_{0}=\sqrt{(9622437-5775815)^{2}}+(9536920-581726)^{2} \\
& +(9416651-5276042)^{2}=45604838245916 \\
& D(p, c)_{0}=\sqrt{(9622437-5647232)^{2}}+(9536920-5659580)^{2} \\
& +(9416651-5430346)^{2}=65394838245916 \\
& D(p, c)_{0}=\sqrt{(9622437-5870871)^{2}}+(9536920-5661924)^{2} \\
& +(9416651-5439344)^{2}=87644838245916
\end{aligned}
$$

\begin{tabular}{|l|l|l|l|l|l|}
\hline Data & C1 & C2 & C3 & C4 & C5 \\
\hline \multirow{4}{*}{ B1 } & 80494 & 67113 & 45604 & 6539 & 8764 \\
& $\begin{array}{l}83824 \\
5916\end{array}$ & $\begin{array}{l}28649 \\
5484\end{array}$ & 5916 & $\begin{array}{l}4838 \\
459\end{array}$ & $\begin{array}{l}2459 \\
16\end{array}$ \\
\hline \multirow{4}{*}{ B2 } & 80389 & 49135 & 47890 & 8494 & 7463 \\
& 19001 & 79054 & 53263 & 8736 & 8275 \\
& 9152 & 5766 & 7284 & 3552 & 3536 \\
B3 & 80386 & 25811 & 69863 & 4739 & 7493 \\
& 58992 & 79891 & 42638 & 3923 & 7634 \\
\hline
\end{tabular}




\begin{tabular}{|l|l|l|l|l|l|}
\hline & 4976 & 5418 & 4353 & 5532 & 2748 \\
76 & 44 \\
\hline & 80329 & 51099 & 74638 & 3629 & 8892 \\
B4 & 65886 & 67801 & 30735 & 2635 & 6537 \\
& 7861 & 9793 & 6282 & 3426 & 5274 \\
80 & 84 \\
\hline & 58848 & 34702 & 53427 & 4648 & 4926 \\
B5 & 88155 & 65464 & 39202 & 3625 & 4527 \\
& 4157 & 2836 & 7354 & 2640 & 2547 \\
& & & 17 & 34 \\
\hline & 80056 & 15725 & 90362 & 8940 & 6038 \\
B6 & 71282 & 07329 & 36453 & 4735 & 4548 \\
& 5809 & 0767 & 8284 & 4745 & 4638 \\
& 80078 & 15181 & 67946 & 7464 & 6583 \\
B7 & 28332 & 85696 & 72794 & 8392 & 3527 \\
& 4574 & 8105 & 7352 & 6542 & 4957 \\
& & 2 & 46 \\
\hline & 55683 & 16576 & 78534 & 1204 & 9074 \\
B8 & 82093 & 01363 & 27365 & 8463 & 5375 \\
& 1942 & 4164 & 4909 & 8363 & 3735 \\
& & & 5 & 52 \\
\hline & 80018 & 44240 & 20183 & 6449 & 5756 \\
B9 & 83880 & 26340 & 3840 & 3832 & 3836 \\
& 7614 & 3375 & 6353 & 4846 \\
& 90076 & 10037 & 60383 & 4639 & 5836 \\
\hline & 89112 & 20912 & 54673 & 4746 & 4835 \\
B10 & 2713 & 1065 & 5363 & 3792 & 4892 \\
0 & 92 \\
\hline
\end{tabular}

8. Klasifikasi kembali data berdasarkan jarak minimum di atas:

\begin{tabular}{|l|l|l|l|l|l|}
\hline Data & C1 & C2 & C3 & C4 & C5 \\
\hline B1 & 0 & 0 & 1 & 0 & 0 \\
\hline B2 & 0 & 0 & 1 & 0 & 0 \\
\hline B3 & 0 & 1 & 0 & 0 & 0 \\
\hline B4 & 0 & 0 & 0 & 1 & 0 \\
\hline B5 & 0 & 1 & 0 & 0 & 0 \\
\hline B6 & 0 & 1 & 0 & 0 & 0 \\
\hline B7 & 0 & 1 & 0 & 0 & 0 \\
\hline B8 & 0 & 0 & 0 & 1 & 0 \\
\hline B9 & 0 & 0 & 1 & 0 & 0 \\
\hline B10 & 0 & 1 & 0 & 0 & 0 \\
\hline
\end{tabular}

Karena ada data yang berpindah ke cluster yang berbeda, sehingga iterasi harus di hitung ulang sampai dengan nilai centroid tidak ada yang berpindah ke cluster yang berbeda.

\section{Pengujian Sistem}

Pengujian sistem merupakan rangkaian uji coba yang terdapt di dalam sistem untuk klasifikasi telur ayam. Pada proses pengujian ini dimaksudkan untuk mengetahui jalannya sistem, apakah sistem 
yang dibuat telah sesuai harapan atau belum. Berikut proses pengujian pada sistem penentuan klasifikasi telur ayam dapat dilihat pada gambar berikut.

\subsection{Halaman Utama}

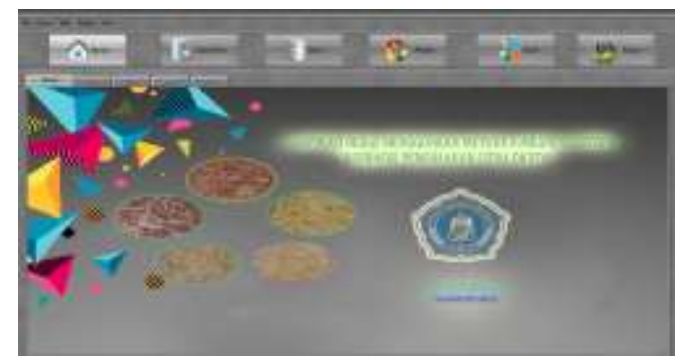

Halaman utama ini dirancang untuk menampilkan judul dan deskripsi pembuat aplikasi diantaranya nama dan nim pembuat aplikasi. Halam utama berfungsi untuk menampilkan tombol home, input data master, analisa, rekap laporan dan keluar.

\subsection{Halaman Lood Citra}

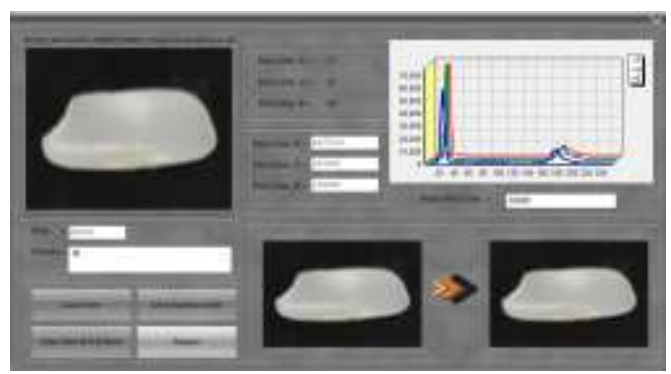

Halaman Load Citra ini digunakan untuk menginput data aturan / data yang digunakan sebagai pembanding nilai yang similar (mirip) satu sama lain dalam cluster dan disimilar (tidak mirip) terhadap objekobjek yang berbeda cluster, sehingga sebelum melakukan analisa harus menginputkan data master terlebih dahulu. Data master sangat berperan penting terhadap hasil analisa, karena nilai RGB telur ayam yang akan dianalisa akan di cocokkan dengan nilai RGB pada data master. Input data master dapat dilakukanoleh pakar dengan login terlebih dahulu.

\subsection{Halaman Data}

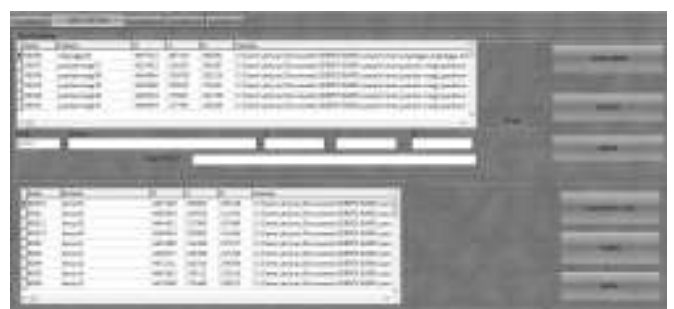

Pada halaman Data ini pengguna aplikasi dapat melakukan klasifikasi. klasifikasi yang dimaksud disini yaitu mengetahui klasifikasi Beras. Pada berbagai menu analisa ini, pengguna dapat melihat gambar Beras yang ingin diketahui nilai RGBnya, dan mengklik tombol perintah secara urut sesuai pada form di atas.

\subsection{Halaman Proses Analisa}



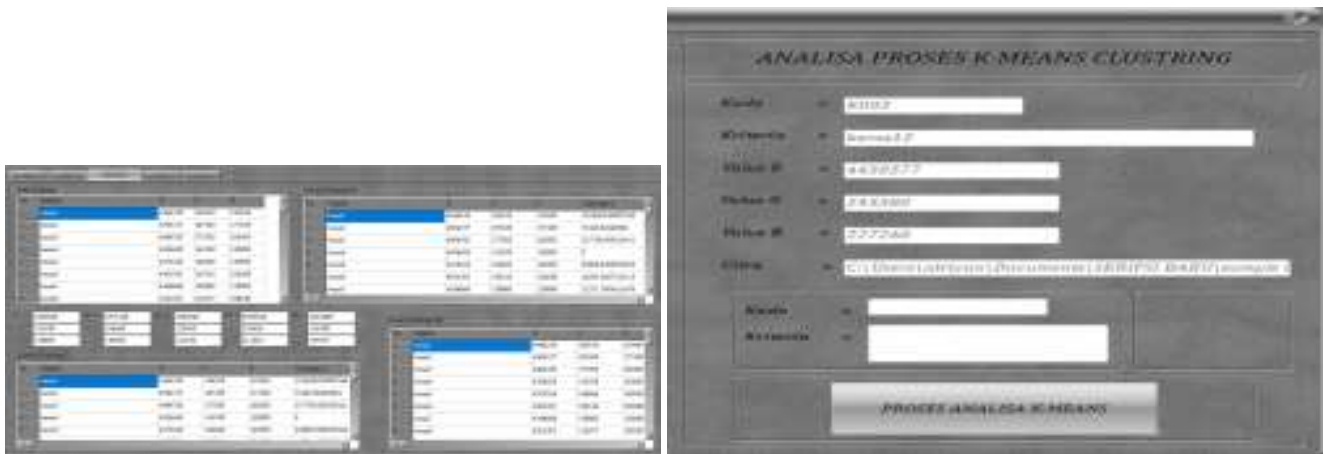

Pada halaman proses pengguna yang telah menginputkan gambar beras dan memilih tombol Proses, maka sistem secara otomatis melakukan perhitungan dengan menggunakan metode $k$-means clustering dan akan menampilkan hasil klasifikasi. Hasil klasifikasi diperoleh dari nilai RGB yang paling similar (mirip) antar nilai RGB beras yang akan di analisa dengan beras yang disimpan pada data master. Hasil analisa ini berupa informasi klasifikasi Beras berdasarkan inputan data yang dimasukkan oleh pengguna aplikasi

\subsection{Uji Coba Menggunakan Black Box Testing}

Pengujian sistem dengan menggunakan black box bertujuan untuk mengetahui jalannya suatu sistem. Dengan melakukan pengujian seperti ini, dapat diketahui hasil dari proses program apakah telah sesuai dengan hasil yang diharapkan, sehingga dapat menghasilkan output yang sesuai dengan hasil tes-tes yang dijalankan. Hasil yang diharapkan disini adalah dengan memasukkan gambar telur ayam dapat diketahui nilai RGBnya, sehingga dengan perbandingan nilai kedekatan antara nilai RGB data master dan data telur yang di analisa dapat menghasilkan informasi berupa klasifikasi telur ayam terhadap pengguna. Berikut adalah hasil pengujian menggunakan black box.

Untuk mengetahui seberapa besar keakuratan sistem maka dilakukan uji coba menggunakan kuisioner antara pendapat responden tentang sistem aplikasi image processing. berdasarkan hasil pengujian kuisioner yang dihasilkan dari sistem aplikasi image processing sebanyak 10 responden maka hasil tingkat keakurasian sistem sebesar $100 \%$ dengan perhitungan sebagai berikut.

10 responden $\mathrm{x} 8$ pertanyaan $\mathrm{x}$ bobot nilai tertinggi $(3)=$

Sangat Setuju

$10 \times 8 \times 3=240$

$93 / 240 \times 100=38.75 \%$ di bulatkan menjadi $39 \%$

Setuju

$10 \times 8 \times 3=240$

$76 / 240 \times 100=31.6 \%$ di bulatkan menjadi $32 \%$

Cukup Setuju

$10 \times 8 \times 3=240$

$15 / 240 \times 100=6.25 \%$ di bulatkan menjadi $7 \%$

Kurang Setuju

$10 \times 8 \times 3=240$

$0 / 240 \times 100=0 \%$

Total Keseluruhan $78 \%$.

Dengan demikian tingkat keakurasian pada pengujian pada black box testing pada aplikasi adalah $78 \%$ yang artinya masih ada kegagalan pada sistem aplikasi yang harus diperbaiki

\subsection{Pengujian Sistem Dengan Pakar}

Berdasarkan hasil pengujian yang dilakukan sebanyak 40 kali terdapat kesalahan sebesar 9 kali dan kesesuaian 31 kali, sehingga dapat disimpulkan bahwa tingkat keakuratan sistem sebanyak 77,5\%

\section{Kesimpulan dan Saran}

\section{Kesimpulan}

Dari penelitian yang telah dilakukan, maka dapat diperoleh kesimpulan: 
1. Dengan menggunakan aplikasi ini masyarakat dapat mengimplmentasikan data berupa gambar, sehingga bisa dimasukkan kedalam aplikasi image processing dengan menggunakan pendekatan metode $k$-means clustering agar masyarakat dapat mengetahui jenis beras.

2. Dari hasil uji coba dengan pakar maka dapat disimpulkan tingkat keakurasian dengan menggunakan metode $k$-means clustering mencapai $77.5 \%$ sehingga aplikasi ini dapat digunakan.

\section{Saran}

Saran untuk penelitian pengembangan selanjutnya:

1. Untuk mengembangkan aplikasi selanjutnya bisa digunakan untuk mengclustering semua citra digital bukan hanya yang berformat $\mathrm{bmp}$.

2. Untuk meningkatkan hasil pengelompokkan citra digital yang lebih relavan sebaiknya algoritma $K$-means digabung dengan algoritma lain, seperti deteksi tekstur atau yang lain dalam pengolahan citra digital (image procceng).

3. Penambahan kamera yang langsung dihubungkan keprogram dan dapat mengambil gambar lalu diproses secara otomatis.

\section{Daftar Pustaka}

Abdul. 2012. Pengujian Perangkat Lunak Dengan Menggunakan Metode White Box Dan Black Box. Semarang

Awaluddin, M dan B.D Yuwono. 2010. Penajaman dan Segmentasi Citra Pada Pengolahan Citra Digital. TEKNIK - Vol. 31 No. 1 Tahun 2010, ISSN 0852-1697, hal:63

Desmanto S, Irwan, dan R. Angreni. 2015. Penerapan Algoritma K-Means Clustering Untuk Pengelompokkan Citra Digital Dengan Ekstraksi Fitur Warna RGB. STMIK GI MDP. Palembang.

Nuryani. Potensi subtitusi beras putih dengan beras merah sebagai makanan pokok untuk perlindungan diabetes militus. Makasar. 